\title{
Deteç̧ão de resíduos de enrofloxacina por ensaio imunoenzimático e cromatografia líquida acoplada à espectrometria de massas em ovos comerciais de galinha após tratamento
}

\author{
[Investigation of enrofloxacin residues through enzyme-linked immunosorbent assay and \\ liquid cromatography-tandem mass spectrometry in eggs from \\ laying hens after treatment] \\ R. Gouvêa ${ }^{1}$, F.F. Santos ${ }^{1}$, L.S. Machado ${ }^{1}$, P.H.N. Panzenhagen ${ }^{1}$, M.H.C. Aquino ${ }^{2}$, \\ E. Rosendo do Nascimento ${ }^{2}$, C. Ribeiro ${ }^{3}$, V.L.A. Pereira ${ }^{2}$ \\ ${ }^{1}$ Aluno de pós-graduação - Faculdade de Veterinária - Universidade Federal Fluminense - UFF - Niterói, RJ \\ ${ }^{2}$ Faculdade de Veterinária - UFF - Niterói, RJ \\ ${ }^{3}$ Laboratório Nacional Agropecuário (LANAGRO) - Porto Alegre, RS
}

\begin{abstract}
RESUMO
A enrofloxacina é um dos antimicrobianos mais utilizados na avicultura industrial, e a deposição de resíduos em produtos avícolas, como os ovos, são de grande importância para a saúde pública. Na legislação brasileira não existe padronização do período de carência para o seu uso na produção avícola e não há Limite Máximo de Resíduo (LMR) fixado para enrofloxacina em ovos. Neste estudo, foi utilizado o kit de ELISA comercial (Bioo Scientific ${ }^{\circledR}$ ) e a LC-MS/MS na pesquisa de enrofloxacina em ovos de 30 galinhas tratadas previamente via água de bebida, com $10 \mathrm{mg} / \mathrm{kg}$ de enrofloxacina, durante cinco dias. Seis ovos foram coletados diariamente e analisados durante o tratamento e após a sua suspensão, durante 15 dias. A deposição de resíduos obteve níveis máximos no quinto dia de tratamento das aves, declinando gradativamente até não ser detectada a partir do nono dia de suspensão do tratamento. Considerando como base o LMR de $100 \mu \mathrm{g} / \mathrm{kg}$ fixado pelo Brasil para tecidos comestíveis de aves e pela União Europeia para músculo, gordura e pele, após seis dias de suspensão do tratamento, os níveis de resíduos

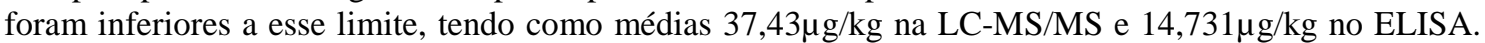
Dentro das condições deste estudo, um período de carência de seis dias seria mais adequado para utilização dos ovos para consumo humano. Foram detectados valores de resíduos nos ovos menores no ELISA em relação à LC-MS/MS para a mesma amostra, mas os dois métodos apresentaram concordância estatística entre si. A LC-MS/MS é o teste recomendado pela legislação brasileira para a análise de resíduos em alimentos; entretanto, pelos resultados obtidos, o kit de ELISA utilizado também pode ser aplicado na deteç̧ão de resíduos de enrofloxacina em ovos, com as vantagens de rapidez e simplicidade.
\end{abstract}

Palavras-chave: enrofloxacina, resíduos, ovos, LC-MS/MS, ELISA

\begin{abstract}
Enrofloxacin is one of the most used antibiotics in the poultry industry and the deposition of residues in poultry products, such as eggs, are of great concern to public health. In Brazilian law there is no standard withdrawal period for enrofloxacin in eggs and there is no Maximum Residue Limit (MRL) established for this antimicrobial in eggs. In this study, (Bioo Scientific $\left.{ }^{\circledR}\right)$ commercial ELISA kit and LCMS/MS were used to investigate enrofloxacin in eggs of 30 hens pretreated via drinking water at $10 \mathrm{mg} / \mathrm{kg}$ of enrofloxacin for five days. Six eggs were collected daily and analyzed during treatment and after the end of treatment, for 15 days. Residues obtained maximum levels on the fifth day of treatment, declined gradually and were no longer detected from the ninth day to the end of treatment. Based on the MRL of $100 \mathrm{mg} / \mathrm{kg}$ established for edible tissues of poultry by Brazillian law and for muscle, fat and skin, by the European Union, after six days of treatment withdrawal, the residue levels were below that limit, with the
\end{abstract}

Recebido em 5 de fevereiro de 2014

Aceito em 7 de agosto de 2014

E-mail: quelgouvea@yahoo.com.br 
average of $37.43 \mathrm{mg} / \mathrm{kg}$ in LC-MS/MS and $14.731 \mathrm{mg} / \mathrm{kg}$ in ELISA. Within the conditions of this study, a withdrawal period of six days would be more appropriate to use the eggs for human consumption. The values obtained by ELISA for residues in eggs were lower than those obtained in LC-MS/MS for the same sample, however both methods showed statistical agreement. LC-MS/MS is the recommended method by Brazilian legislation for analysis of residues in food, however, according to the results the ELISA kit used can also be applied to the detection of enrofloxacin residues in eggs, with the advantages of speed and simplicity.

Keywords: enrofloxacin, residues, eggs, LC-MS/MS, ELISA

\section{INTRODUÇÃO}

A enrofloxacina é um antimicrobiano bactericida de uso exclusivo em Medicina Veterinária, bastante utilizada na avicultura industrial e atua através da inibição da atividade catalítica das enzimas bacterianas DNA girase (ou Topoisomerase II) e Topoisomerase IV, que são essenciais à replicação e transcrição do DNA bacteriano (Sharma et al., 2009). A ciprofloxacina é um dos metabólitos da enrofloxacina, farmacocineticamente diferente, com metade ou menos da metade da biodisponibilidade no organismo da ave, e é utilizada na medicina humana (Ito et al., 2005).

Além de o uso de antibacterianos em animais ter suscitado questões como a resistência bacteriana, outra preocupação importante é a possibilidade da presença de resíduos nos produtos avícolas e os riscos inerentes ao consumo desses resíduos pela população. A Comissão do Codex Alimentarius recomenda um Limite Máximo de Resíduos (LMR) a ser legalmente permitido em um alimento, que é a concentração máxima de resíduos expressa em $\mathrm{mg} / \mathrm{kg}$ ou $\mu \mathrm{g} / \mathrm{kg}$ (Codex Alimentarius, 2011) e são parâmetros importantes na determinação do período de carência de um medicamento (Palermo Neto, 2005). Entre as formulações de enrofloxacina existentes no país, de um modo geral não há um padrão de recomendação quanto aos períodos de carência descritos nas bulas, o que permite interpretações variadas e a utilização indevida desse medicamento nas aves. Como consequência, o risco de haver níveis elevados de resíduos nos ovos pode ser maior, assim como pode ser maior o risco de o consumidor ficar exposto a essas substâncias.

A União Europeia proíbe o uso de enrofloxacina em aves cujos ovos destinam-se ao consumo humano, e possui como LMR fixados para músculo, gordura e pele de aves, $100 \mu \mathrm{g} / \mathrm{kg}$,
$200 \mu g / \mathrm{kg}$ para fígado e $300 \mu \mathrm{g} / \mathrm{kg}$ para rins (European Community, 2002a). No Brasil, o LMR fixado para tecidos comestíveis de aves é de $100 \mu \mathrm{g} / \mathrm{kg}$ para ciprofloxacina + enrofloxacina (Brasil, 2013). Quanto à matriz ovo, o limite de referência usado pelo Ministério da Agricultura, Pecuária e Abastecimento (MAPA), no Subprograma de Monitoramento de Controle de Resíduos de Contaminantes em Ovos, é de $10 \mu \mathrm{kg}$ para enrofloxacina e ciprofloxacina. Como se trata de substância registrada para uso em aves de postura, mas seu respectivo LMR não está estabelecido pela legislação vigente, o limite de referência para tomada de ação regulatória gerencialmente adotado é igual a $10 \mu \mathrm{g} / \mathrm{kg}$ ou $10 \mu \mathrm{g} / \mathrm{L}$, pois é a menor concentração detectável pelos testes aceitos pela legislação (Brasil, 2013).

Em aves de postura, a presença de resíduos em ovos é motivo de preocupação, pois os ovos podem conter resíduos de uma grande variedade de drogas, que podem ser detectáveis dias a semanas após o término do tratamento das galinhas (Goetting et al., 2011).

Dentre os três componentes principais do ovo gema, albúmen e casca -, a gema tem maior tempo de desenvolvimento. Precursores das lipoproteínas da gema são produzidos no fígado e transportados através da circulação para os folículos da gema no ovário. Em uma galinha de postura ativa, vários folículos em diferentes estágios de desenvolvimento residem simultaneamente no ovário. Antes de um ovo ser colocado, a gema sofre uma fase de crescimento rápido, em que aumenta de tamanho exponencialmente durante dez dias (Etches, 1996). Drogas que se depositam na gema irão se acumular rapidamente durante esse tempo e podem se apresentar em ovos postos, sucessivamente, por dez ou mais dias após o término do tratamento. Após a maturação da gema, o albúmen é posto ao longo de um período de duas a três horas e é adicionado após 
proteínas do albúmen serem depositadas e diluídas em água (Etches, 1996; Whittow, 2000) e também serve como um local de acumulação de resíduo. Drogas que são eliminadas rapidamente do organismo também são eliminadas do albúmen em dois a três dias após o fim da exposição à droga, ao passo que, na gema, essa eliminação ocorre em torno de 10 dias (Kan e Petz, 2000).

Resíduos de fluoroquinolonas aparecem nos ovos após cerca de 24 horas da primeira dose e persistem na gema e no albúmen durante vários dias após o término do tratamento (Etches, 1998).

Oficialmente, a análise de resíduos de fluoroquinolonas em alimentos é realizada por meio da Cromatografia Líquida de Alta Eficiência (HPLC) acoplada à espectrometria de massas (LC-MS/MS) (Brasil, 2011), utilizada na quantificação em análises de alimentos por sua alta especificidade, sensibilidade e ampla aplicabilidade, dando-lhe a capacidade de analisar múltiplos resíduos em um único procedimento (Botsoglou; Fletouris, 2001. No entanto, é uma técnica sofisticada que demanda pessoal altamente capacitado e equipamento de elevado custo. As técnicas imunológicas, especialmente o Ensaio Imunoenzimático (ELISA, do inglês "Enzyme-linked immunosorbent assay”), estão cada vez mais sendo utilizadas como métodos alternativos e/ou complementares na análise de resíduos em função de sua rapidez, custo-benefício, portabilidade e aplicabilidade, principalmente como métodos de triagem (Zhang, 2011).

Este estudo teve como objetivo pesquisar resíduos de enrofloxacina em ovos de galinhas previamente tratadas com esse antimicrobiano por meio do ELISA e da LC-MS/MS.

\section{MATERIAL E MÉTODOS}

Foram utilizadas neste estudo um total de 30 galinhas poedeiras brancas, da linhagem Lohmann LSL, com 18 meses de idade e média de peso de $1.520 \mathrm{~g}$, adquiridas de criação de postura comercial convencional em gaiolas, localizada na região Serrana do Estado do Rio de Janeiro. As aves foram transportadas à instalação experimental e nela mantidas por um período inicial de 20 dias para adaptação e minimização do estresse sofrido pelo transporte e posteriormente por mais 40 dias, totalizando 60 dias de experimento. As aves foram mantidas sobre piso coberto por cama de maravalha, em instalação própria, em uma unidade experimental preparada para este experimento e receberam acesso ad libitum à água e à ração.

Os animais foram tratados de acordo com os Princípios Éticos na Experimentação Animal da Sociedade Brasileira de Ciência em Animais de Laboratório (SBCAL) e o projeto foi certificado pelo Comitê de Ética no Uso de Animais da Universidade Federal Fluminense, sob o número de processo 291.

As aves receberam uma dose de $10 \mathrm{mg} / \mathrm{kg}$ de peso vivo de enrofloxacina, administrada via água de bebida durante cinco dias consecutivos. O período de carência estipulado em bula para o medicamento utilizado no experimento foi de três dias para o consumo de ovos.

Antes do tratamento foi feita uma análise dos ovos postos para assegurar que não havia resíduos de enrofloxacina. Posteriormente, os ovos foram coletados nos seguintes momentos: do primeiro ao quinto dia de tratamento (seis ovos por dia) e do primeiro ao $15^{\circ}$ dia subsequentes ao tratamento (seis ovos por dia). As amostras foram então transportadas, em bandejas próprias para ovos, ao laboratório de Sanidade Avícola da Faculdade de Medicina Veterinária da UFF, onde foi realizado o ELISA e o preparo e acondicionamento das amostras para envio ao LANAGRO-RS, onde se realizou a LC-MS/MS. Cada unidade amostral consistiu no homogeneizado de um ovo íntegro, ou seja, gema e clara.

O ELISA foi realizado no Laboratório de Sanidade Avícola, na Faculdade de Veterinária da Universidade Federal Fluminense, por meio do kit comercial "Enrofloxacin ELISA test kit" (Max Signal ${ }^{\circledR}$ Enrofloxacin ELISA test kit \#1017-03, Bioo Scientific, Estados Unidos), que detecta a soma de resíduos de enrofloxacina + ciprofloxacina, e o seu método baseia-se no ELISA competitivo. $\mathrm{O}$ teste apresenta reação cruzada com ciprofloxacina (100\%), danofloxacina (32\%), enoxacina (14\%), ácido pipemídico (11\%), ofloxacina (7\%), benofloxacina (3\%), ácido oxonílico (4\%) e ácido nalidíxico (2\%). 
O kit apresentou como controles internos as seguintes concentrações de enrofloxacina: $0 \mu \mathrm{g} / \mathrm{kg}, 0,35 \mu \mathrm{g} / \mathrm{kg}, 1,0 \mu \mathrm{g} / \mathrm{kg}, 2,5 \mu \mathrm{g} / \mathrm{kg}, 7,5 \mu \mathrm{g} / \mathrm{kg}$ e $22,5 \mu \mathrm{g} / \mathrm{kg}$. O limite de detecção do teste nas matrizes analisadas foi de $3,5 \mu \mathrm{g} / \mathrm{kg}$, utilizou-se o fator de diluição 10 , e a metodologia seguiu as recomendações do fabricante.

Resumidamente, 1,0g das amostras homogeneizadas foi submetido à extração com metanol 70\%. Após homogeneização e centrifugação a $4.000 \mathrm{~g}$ por cinco minutos à temperatura ambiente, $0,5 \mathrm{~mL}$ dos sobrenadantes foi transferido para microtubos em polipropileno, em que foi adicionado $0,5 \mathrm{~mL}$ de solução de extração fornecido pelo kit e homogeneizado. Para o teste foram utilizadas alíquotas de $50 \mu \mathrm{L}$ de cada amostra. A leitura espectrofotométrica foi realizada a $450 \mathrm{~nm}$ em leitor de microplaca TP-reader ${ }^{\circledR}$ (Thermo Plate, China).

A Cromatografia Líquida acoplada à Espectrometria de Massas Sequencial (LC-MS/MS) foi realizada no Laboratório de Análise de Resíduos de Pesticidas e Medicamentos Veterinários do Laboratório Nacional Agropecuário (LANAGRO) no Estado do Rio Grande do Sul. Foi utilizada metodologia de determinação de Fluoroquinolonas em ovos por LC-MS/MS, validada de acordo com a Diretiva 2002/657/EC (European Comission, 2002b).

O limite de detecção (LOD) de todos os analitos foi de $10 \mu \mathrm{g} / \mathrm{kg}$ e o de quantificação (LOQ) foi $20 \mu \mathrm{g} / \mathrm{kg}$. O limite de decisão ( $\alpha \mathcal{C}$ na matriz ovo para ciprofloxacina foi de $10,93 \mu \mathrm{g} / \mathrm{kg}$ e $10,86 \mu \mathrm{g} / \mathrm{kg}$ para enrofloxacina. A capacidade de detecção (q) foi de $11,53 \mu \mathrm{g} / \mathrm{kg}$ para ciprofloxacina e 11,42 $\mu \mathrm{g} / \mathrm{kg}$ para enrofloxacina, na matriz ovo.

Foram utilizados como reagentes acetonitrila e ácido fórmico grau HPLC, água ultra-pura e os padrões de ciprofloxacina, norfloxacina, enrofloxacina, enrofloxacina-D5 (deuterado), sarafloxacino, difloxacino, flumequina, ácido nalidíxico, ácido oxolínico e danofloxacino com pureza mínima de 95\%. Todos os analitos foram pesquisados, mas somente enrofloxacina + ciprofloxacina foram reportados.

A curva de calibração foi preparada por meio da adição das soluções de fortificação diretamente sobre matriz branca (Tab. 1).

Tabela 1. Concentrações dos níveis de fortificação para curva preparada em matriz para amostras de 2g de ovo

\begin{tabular}{ccccc}
\hline $\begin{array}{c}\text { Níveis de } \\
\text { fortificação }\end{array}$ & $\begin{array}{c}\text { Soluções de Fortificação } \\
1 \text { e } 2(\mu \mathrm{L})\end{array}$ & $\begin{array}{c}\text { PI } 10 \mu \mathrm{g} \cdot \mathrm{mL}^{-1} \\
(\mu \mathrm{L})\end{array}$ & $\begin{array}{c}\text { Concentração } \\
\text { amostra ng.g }^{-1}\end{array}$ & $\begin{array}{c}\text { Concentração } \\
\text { amostra ng.g }^{-1}\end{array}$ \\
\hline Ponto 1 & 0 & 20 & 0 & 0 \\
Ponto 2 & 4 & 20 & 2 & 20 \\
Ponto 3 & 10 & 20 & 5 & 50 \\
Ponto 4 & 20 & 20 & 10 & 100 \\
Ponto 5 & 30 & 20 & 15 & 150 \\
Ponto 6 & 40 & 20 & 20 & 200 \\
\hline
\end{tabular}

PI - padrão interno.

Para o preparo das amostras, 2,0 $\pm 0,1 \mathrm{~g}$ de cada amostra de ovo previamente homogeneizado foram acondicionados em tubo cônico em polipropileno de $50 \mathrm{~mL}$ de capacidade. Para a extração das amostras, foram adicionados $10 \pm 0,5 \mathrm{~mL}$ de acetonitrila acidificada com $1 \%$ de ácido fórmico em cada tubo contendo a amostra. As amostras foram homogeneizadas e mantidas sob agitação em mesa agitadora por aproximadamente 20 minutos. Em seguida, foram submetidas à centrifugação sob refrigeração a $2.000 \mathrm{~g}$, por aproximadamente 10 minutos. O sobrenadante foi então transferido para tubo cônico em polipropileno de $50 \mathrm{~mL}$, e $1 \mathrm{~mL}$ do extrato foi transferido para microtubo em polipropileno. Para o preparo de amostras tipo TS ("Tissue Standard"), foram transferidos $996 \mu \mathrm{L}$ do extrato para microtubo fortificando com $2 \mu \mathrm{L}$ das soluções de fortificação (PI e Pool). As amostras foram então mantidas sob congelamento por 60 minutos e então centrifugadas a $10.000 \mathrm{~g}$, por aproximadamente 10 minutos. Foram então transferidos $800 \mu \mathrm{L}$ de fase móvel A (Água 0,1\% ácido fórmico) para os vials e adicionados $200 \mu \mathrm{L}$ de extrato. A análise foi submetida em sistema LC-MS/MS API 5000. 
A cromatografia foi realizada em Sistema Agilent 1100 Series, fluxo de fase móvel em 0,3 $\mathrm{mL} / \mathrm{min}$, coluna C18, Xterra endcapped $3.5 \mu \mathrm{m}$ $125 \AA 100$ X 2,1mm. A fonte de ionização foi Electrospray em modo positivo (ESI+). Os dados foram obtidos por meio do software Analyst ${ }^{\circledR}$ (Applied Biosystems, Canadá). O tempo de equilíbrio da coluna foi de 4 minutos ao final de cada corrida, e o volume de injeção foi $10 \mu \mathrm{L}$.

O delineamento experimental utilizado neste estudo foi o Delineamento Inteiramente ao acaso (DIC). A Análise de Variância foi utilizada para comparação entre os valores obtidos nos dois métodos. As médias obtidas nos dois métodos foram submetidas à análise não paramétrica pelo teste de Kruskal-Wallis e o método de Dunn. O Coeficiente de Correlação de Pearson (r) foi utilizado para medir o grau da correlação linear entre as duas variáveis quantitativas. Utilizou-se o software GraphPad InStat, versão 3.10, em todas as análises estatísticas, com intervalo de confiança fixado em $95 \%$.

\section{RESULTADOS E DISCUSSÃO}

O primeiro pico de concentração de enrofloxacina foi observado após 24 horas do primeiro dia de administração do medicamento às aves (Tab. 2). As médias encontradas de resíduos nos ovos foram 828,902 $\mu \mathrm{g} / \mathrm{kg}$ e $1620,828 \mu \mathrm{g} / \mathrm{kg}$, no ELISA e na LC-MS/MS, respectivamente, e se elevaram gradativamente até obterem pico máximo ao quinto dia de tratamento, alcançando 1065,317 no ELISA e $2947,06 \mu g / \mathrm{kg}$ na LC-MS/MS. Com o fim do tratamento, as médias de resíduos continuaram elevadas no primeiro dia pós-tratamento, ou seja, $772,9 \mu \mathrm{g} / \mathrm{kg}$ no ELISA e $1725,33 \mu \mathrm{g} / \mathrm{kg}$ na LCMS/MS, e a depleção ocorreu de forma gradativa até não ser mais detectado a partir do nono dia de suspensão.

Tabela 2. Médias e desvios padrões dos resíduos conjuntos de ciprofloxacina e enrofloxacina em $\mu \mathrm{g} / \mathrm{kg}$ em ovos por LC-MS/MS e ELISA, por dia, durante e após a medicação das galinhas

\begin{tabular}{|c|c|c|c|c|c|}
\hline \multirow{2}{*}{\multicolumn{2}{|c|}{$\begin{array}{l}\text { Momento de coleta dos } \\
\text { ovos }\end{array}$}} & \multirow{2}{*}{$\frac{\text { LC-MS/MS }}{\text { Média }^{1}}$} & \multirow[b]{2}{*}{$\begin{array}{l}\text { Desvio } \\
\text { padrão }\end{array}$} & \multicolumn{2}{|c|}{ ELISA $^{2}$} \\
\hline & & & & Média ${ }^{1}$ & $\begin{array}{l}\text { Desvio } \\
\text { padrão }\end{array}$ \\
\hline \multirow{5}{*}{$\begin{array}{c}\text { Dias } \\
\text { Durante o } \\
\text { Tratamento }\end{array}$} & 1 & $<\mathrm{LOD}^{*}$ & & $<\mathrm{LOD}^{* * *}$ & \\
\hline & 2 & 1620,82 & 820,92 & 828,90 & 320,60 \\
\hline & 3 & 1997,33 & 747,13 & 803,69 & 187,43 \\
\hline & 4 & 1692,5 & 1381,22 & 778,05 & 212,50 \\
\hline & 5 & 2947,06 & 358,98 & 1065,31 & 210,90 \\
\hline \multirow{16}{*}{$\begin{array}{l}\text { Dias Após o } \\
\text { Tratamento }\end{array}$} & 1 & 1725,33 & 1012,85 & 772,95 & 349,06 \\
\hline & 2 & 1297,17 & 318,41 & 693,99 & 220,39 \\
\hline & 3 & 644,23 & 229,25 & 258,23 & 134,34 \\
\hline & 4 & 530,13 & 244,13 & 133,38 & 41,42 \\
\hline & 5 & 249,77 & 39,83 & 85,84 & 47,57 \\
\hline & 6 & 169,35 & 74,76 & 92,24 & 53,44 \\
\hline & 7 & 37,43 & 17,89 & 14,73 & 4,78 \\
\hline & 8 & 18,52 & 2,94 & 11,59 & 3,58 \\
\hline & 9 & 9,62 & 4,73 & 4,67 & 2,04 \\
\hline & 10 & $<\mathrm{LOD}^{*}$ & & 5,42 & 4,61 \\
\hline & 11 & $<\mathrm{LOD}^{*}$ & & 3,78 & 3,29 \\
\hline & 12 & $<\mathrm{LOD}^{*}$ & & $<\mathrm{LOD}^{* *}$ & \\
\hline & 13 & $<\mathrm{LOD}^{*}$ & & $<\mathrm{LOD}^{* *}$ & \\
\hline & 14 & $<\mathrm{LOD}^{*}$ & & $<\mathrm{LOD}^{* *}$ & \\
\hline & 15 & $<\mathrm{LOD}^{*}$ & & $<\mathrm{LOD}^{* *}$ & \\
\hline & $\begin{array}{l}\text { Média } \\
\text { Global }\end{array}$ & 849,35 & & 362,70 & \\
\hline
\end{tabular}

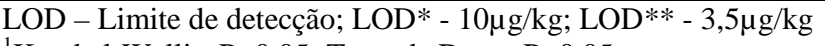

${ }^{1}$ Kruskal-Wallis, $\mathrm{P}<0,05$; Teste de Dunn, $\mathrm{P}>0,05$

${ }^{2}$ Correlação de Pearson, $\mathrm{r}=0,79 ; \mathrm{P}<0,05$ 
A cinética da depleção dos resíduos de enrofloxacina nos ovos pode ser atribuída à formação e composição dos ovos. Proteínas solúveis da clara são formadas e secretadas no magnum, e esse processo leva de um a dois dias. A gema é principalmente composta por lipoproteínas produzidas no fígado, e sua formação leva de oito a 10 dias, no mínimo (Kan e Petz, 2000). Desse modo, a deposição de resíduos na gema continua ocorrendo mesmo após a descontinuidade do tratamento, e por isso é possível detectar resíduos nos ovos em altas concentrações dias após o término do tratamento, como foi verificado neste trabalho. Esse comportamento na curva de depleção de resíduos de enrofloxacina em ovos também foi verificado em estudos de Gorla et al. (1997), Lolo et al. (2005) e Cornejo et al. (2011).

Embora o período de carência recomendado na bula do antimicrobiano utilizado no tratamento das aves fosse de três dias, ao quarto dia póstratamento, a média no ELISA foi de $133,38 \mu \mathrm{g} / \mathrm{kg}$ e na LC-MS/MS, 530,13 $\mu \mathrm{g} / \mathrm{kg}$ (Tab. 2). Esses resultados indicam que os ovos estavam inapropriados para o consumo humano após a carência de três dias, considerando o LMR de $100 \mu \mathrm{g} / \mathrm{kg}$ fixado para tecidos comestíveis de aves, pelo Brasil (Brasil, 2013), e para músculo, gordura e pele de aves, pela União Europeia (European Community, 2002a), como um padrão comparativo para os ovos.

Nesse mesmo raciocínio, após seis dias de carência, os níveis de resíduos foram inferiores ao LMR de $100 \mu \mathrm{g} / \mathrm{kg}$, tendo como médias $37,43 \mu \mathrm{g} / \mathrm{kg}$ na LC-MS/MS e $14,731 \mu \mathrm{g} / \mathrm{kg}$ no ELISA (Tab. 2). Dentro das condições deste estudo, um período de carência de seis dias seria o mais adequado para a utilização dos ovos para consumo humano.

Gorla et al. (1997) também compararam seus resultados ao LMR de $100 \mu \mathrm{g} / \mathrm{kg}$ estabelecido pela UE para músculo, gordura e pele, e propuseram um período de carência para ovos de seis dias para enrofloxacina e cinco para ciprofloxacina após tratarem aves com a metade da dose terapêutica de enrofloxacina utilizada no presente estudo. Utilizando dose de enrofloxacina superior, ou seja, $12 \mathrm{mg} / \mathrm{kg}$ durante cinco dias, Lolo et al. (2005) trataram galinhas poedeiras por via oral e, pelos de seus resultados, com nove dias de carência, os níveis de resíduos de enrofloxacina e ciprofloxacina estavam inferiores ao LMR. Em estudo de Cornejo et al. (2011), sete dias de carência foram suficientes para que os resíduos de enrofloxacina e ciprofloxacina estivessem aquém do LMR de $100 \mu \mathrm{g} / \mathrm{kg}$. Em contrapartida, em estudo de Elkholy et al. (2009), em apenas quatro dias já não foi mais possível detectar resíduos de enrofloxacina nos ovos e isso se deveu ao uso de uma metodologia com sensibilidade inferior para detecção dos resíduos, que foi a microbiológica. Essa variabilidade entre as depleções de resíduos de enrofloxacina pode ser atribuída à variabilidade entre as condições de tratamento das aves de cada experimento e aos métodos e condições analíticas.

Pela análise dos dados do ELISA e da LCMS/MS, as variâncias obtidas foram desiguais (ANOVA). Os valores obtidos para os resíduos foram diferentes $(\mathrm{P}<0,05)$ em cada método de detecção, sendo essas diferenças assinaladas pelo Teste de Kruskal-Wallis; entretanto essas diferenças foram consideradas não significativas ao Teste de Dunn. Ao comparar o desempenho dos métodos de detecção de resíduos pela Correlação de Pearson, houve grande concordância entre eles $(r=0,79, \mathrm{P}<0,05)$.

Pela legislação brasileira, a LC-MS/MS é o teste recomendado para a análise de resíduo em alimentos; entretanto, pelos resultados obtidos neste estudo, o kit de ELISA utilizado também pode ser aplicado na detecção de resíduos de enrofloxacina em ovos, com as vantagens de rapidez e simplicidade.

\section{CONCLUSÕES}

A depleção de resíduos de enrofloxacina nos ovos ocorreu de forma gradativa. No entanto, o seu consumo após o período de carência estipulado em bula poderia constituir risco à saúde humana, se o LMR para tecidos edíveis fosse considerado como base. O kit de ELISA testado pode ser utilizado para análise de resíduos de enrofloxacina em ovos. 


\section{REFERÊNCIAS}

BOTSOGLOU, N. A; FLETOURIS, D. J. Drug Residues In Foods: Pharmacology, Food Safety,and Analysis. New York: Marcel Dekker, 2001, 154p.

BRASIL. Ministério da Agricultura, Pecuária e Abastecimento. Secretaria de Defesa Agropecuária. Análise de resíduos e contaminantes em alimentos. Brasília: MAPA/ACS, 2011, 32p.

BRASIL. Ministério da Agricultura, Pecuária e Abastecimento. Instrução Normativa $\mathrm{n}^{\circ} 17$, de 31 de maio de 2013. Diário Oficial da República Federativa do Brasil, Brasília, DF, 2013, Seção 1.

CODEX ALIMENTARIUS. Joint FAO/WHO

Food Standards Programme Codex Alimentarius Commission. Procedural Manual 20th Edition World Health Organization, Food and Agriculture Organization of the United Nations, Roma, 2011. Disponível em: <http://www.codexalimentarius.net/ web/procedural_manual.jsP > Acessado em: 30 out. 2012

CORNEJO, J.; LAPIERRE, L.; IRAGUEN, D. et al. Study of enrofloxacin and flumequine residues depletion in eggs of laying hens after oral administration. J. Vet. Pharmacol. Ther., v.35, p.67-72, 2011. Disponível em: http://www.ncbi.nlm.nih.gov/pubmed/21392039 Acessado em: 2 out. 2012

ELKHOLY, H.M.; ELKOMY, A.A.; AWIDAT, S.K. et al. Tissue and Egg Residues and Adverse Effect of Two Oral Enrofloxacin Preparations; Baytril ${ }^{\circledR}$ and Enrotryl ${ }^{\circledR}$. Global Veterinaria, v.3, p.363-368, 2009. Disponível em: http://www.idosi.org/gv/gv3(5) 09/2.pdf Acessado em: 24 out. 2012

ETCHES, R.J. Reproduction in Poultry. 1.ed. Wallingford: CAB International, 1998. 318p.

EUROPEAN COMMUNITY. Commission Regulation (EC) $\mathrm{N}^{0} 1181 / 2002$ of 1 July 2002. Official Journal of the European Communities. L172, p.13-20, 2002a.

EUROPEAN COMMUNITY. Commission Decision 2002/657/EC of 12 august 2002. Oficial Journal of the European Communities, L221/8, 2002b.

GOETTING, V.; LEE K.A.; TELL, L.A Pharmacokinetics of veterinary drugs in laying hens and residues in eggs: a review of the literature. $J$. Vet. Pharmacol. Ther., v.34, p.521-556, 2011. Disponível em: http://www.ncbi.nlm.nih.gov/pubmed/21679196 Acessado em: 15 abr. 2012
GORLA, N.; CHIOSTRI, E.; UGNIA, L. et al. HPLC residues of enrofloxacin and ciprofloxacin in eggs of laying hens. Int. J. Antimicrob. Agents, v.8, p.253-256, 1997. Disponível em: <http://www.ncbi.nlm.nih.gov/pubmed/18611811> Acessado em: 02 out. 2012

ITO, N.M.K.; MIYAJI, C.I.; LIMA, E.A. et al. Antimicrobianos: usos preventivos e curativos em avicultura. In: PALERMO NETO, J. et al. Farmacologia Aplicada à Avicultura. 1.ed. São Paulo: Roca, 2005. Cap.8, p.115-147.

KAN, C.A.; PETZ, M. Residues of Veterinary Drugs in Eggs and Their Distribution between Yolk and White. J. Agric. Food Chem., v.48, p.6397-6403, 2000. Disponível em: <http://www.ncbi.nlm.nih.gov/pubmed/11141291> Acessado em: 02 abr. 2012

LOLO, M.; PEDREIRA, S.; FENTE, C. et al. Study of Enrofloxacin Depletion in the Eggs of Laying Hens Using Diphasic Dialysis Extraction/Purification and Determinative HPLC-MS Analysis. J. Agric. Food Chem., v.53, p.2849-2852, 2005. Disponível em: <http://www.ncbi.nlm.nih.gov/pubmed/15826029> Acessado em: 02 out. 2012

PALERMO NETO, J. Resíduos de medicamentos veterinários em carne de frango e ovos. In: PALERMO NETO, J. et al. Farmacologia Aplicada à Avicultura. 1.ed. São Paulo: Roca, 2005. Cap.19, p.287-302.

SHARMA, P.C.; JAIN, A.; JAIN, S. Fluoroquinolone antibacterials: a review on chemistry, microbiology and therapeutic prospects. Acta Pol Pharm., v.66, p.587-604, 2009. Disponível em: http://www.ncbi.nlm.nih.gov/pubmed/20050522.

Acessado em: 13 out. 2012

WHITTOW, G.C. Sturkie's Avian Physiology. 5.ed. San Diego: Academic Press, 2000. 685p.

ZHANG, HAI-TANG; JIANG, JIN-QING; WANG, ZI-LIANG et al. Development of an indirect competitive ELISA for simultaneous detection of enrofloxacin and ciprofloxacin. $J$ Zhejiang Univ-Sci B (Biomed \& Biotechnol), v.12, p.884-891, 2011. Disponível em: http://www.ncbi.nlm.nih.gov/pmc/ articles/PMC3208167/ Acessado em: 27 ago. 2013 